\title{
Differences in Activity in Cerebral Methyltransferases and Monoamine Oxidases Between Audiogenic Seizure Susceptible and Resistant Mice and Deermice
}

\author{
R. L. DOYLE AND O. Z. SELLINGER \\ Laboratory of Neurochemistry, Mental Health Research Institute, University of Michigan, Ann Arbor, MI 48109
}

Received 21 May 1980

\begin{abstract}
DOYLE, R. L. AND O. Z. SELLINGER. Differences in activity in cerebral methyltransferases and monoamine oxidases between audiogenic seizure susceptible and resistant mice and deermice. PHARMAC. BIOCHEM. BEHAV. 13(4) 589591,1980 . - The specific activity of cerebral histamine $\mathrm{N}$-methyltransferase (HMT) was significantly lower in the audiogenic seizure-susceptible (SS) 21-day old DBA/2J mouse when compared to the non-susceptible 70-day old DBA/2J mouse but not when compared to the seizure-resistant (SR) C57Bl/6J mouse at 21 days of age. There was no significant difference between the two strains at 70 days of age. The lower HMT specific activity was also observed in a SS mutant of the deermouse Peromyscus maniculatus, relative to the SR, wild-type animal. The activity of cerebral catechol-Omethyltransferase (COMT) was significantly lower in the DBA/2J mice relative to the C57B1/6J at 21 and 70 days while, in Peromyscus, it was higher in the SS mutant than in the SR animal. The activity of MAO, B was lower in the 21-day old, relative to the 70-day old DBA/2J and the 21-day old C57Bl/6J mice. There were no differences in MAO A or B between SS and SR Peromyscus. The findings raise the possibility that cerebral methylation may operate at characteristic rates in SS animals.
\end{abstract}

Brain methyltransferases MAO Audiogenic seizures Mus Peromyscus

RECENT evidence obtained in our laboratory points to the involvement of methylation in the cellular response of brain tissue to the convulsant agent L-methionine-dl-sulfoximine (MSO) $[14,15]$. Both the in vivo methylation of cerebral histamine by histamine $\mathrm{N}$-methyltransferase (HMT) [16] and the methylation of transfer ribonucleic acids (tRNA) by cerebral tRNA-methyltransferases [3,13] appear to be significantly elevated $[13,16]$ and the substrate specificity of some of the indiviudal tRNA methyltransferases [3] altered in the epileptogenic MSO brain. These observations have raised the possibility that methyl group transfer reactions operate in the MSO epileptogenic brain cells at characteristic levels, possibly "marking" the preconvulsant state biochemically.

In an attempt to ascertain the involvement of methyl group transfer reactions in an animal model with a genetically determined, rather than a chemically elicited, seizure response, two inbred strains of Mus with varying degrees of audiogenic seizure susceptibility and an autosomal recessive audiogenic seizure-susceptible mutant of the deermouse Peromyscus maniculatus bairdii $[1,4]$ were compared by determining the levels of their cerebral HMT activity. In view of the dissimilar distribution of HMT and of another methyltransferase, catechol-O-methyltransferase, (COMT) throughout a number of (rat) brain structures [11], the activity of cerebral COMT was also compared between seizure-susceptible (SS) and -resistant (SR) animals. Furthermore, since the methylated products formed via HMT and COMT action undergo oxidative deamination by monoamine oxidases (MAO), the A and B forms of this enzyme activity were also determined in the Mus and Peromyscus brains.

\section{Animals}

Males of the DBA/2J and C57Bl/6J inbred strains and the mutant epileptic (epep) Peromyscus used throughout the study were obtained from stocks maintained at the Mammalian Genetics Center of the University of Michigan, Ann Arbor, Michigan. The wild-type, SR (EpEp) deermice were wild-conceived animals obtained from Dr. L. Masters, Museum of Zoology, University of Michigan, Ann Arbor, MI. The animals received "Teklan $4 \%$ mouse and rat diet" and water ad lib and were housed in stainless steel cages, $1-6 /$ cage.

The DBA/2J mice were examined at 21 days of age, the peak of audiogenic seizure susceptibility and intensity [17] and at 70 days by which time they have become SR. C57Bl/6J mice, generally SR at all ages [17], were compared to the DBA/2J mice at 21 and 70 days, as "negative controls." The SS deermice were derived from homozygous matings (epep $\times$ epep) and were tested individually for clonic or tonic seizure response at least once after weaning using the key-jingling procedure of Barto [1]. The epep animals 
were compared to the wild-type EpEp Peromyscus who are generally $\mathrm{SR}$ at all ages $[1,4]$

\section{METHOD}

The activities of HMT, COMT, and MAO, types A and B were determined by the procedures of Schatz and Sellinger [15], Porcher and Heller [11], and Owen et al. [10], respectively. Protein was determined according to Lowry et al. [8]. Enzyme activity is expressed as specific activity in nmoles of product $/ \mathrm{h} / \mathrm{mg}$ of protein. Closely analogous results were obtained by expressing the data in nmoles/hr/g of wet tissue (not shown). HMT was determined on whole brain homogenates and on high-speed supernatants prepared by centrifuging 1:10 (w/v) homogenates in $0.25 \mathrm{M}$ sucrose at $104,000 \times \mathrm{g}$ for $30 \mathrm{~min}$. It has been previously demonstrated [19] that, in Swiss-Webster mice approximately $50 \%$ of the homogenate HMT activity is recovered in the high-speed supernatant. It should be noted that all enzyme activities were determined on tissue samples obtained from individual brains.

The statistical significance was determined using Students $t$-test and the 0.05 level of significance was selected using the "two-tailed" test.

\section{RESULTS AND DISCUSSION}

Results of a survey of HMT activity in the brains of $\mathrm{DBA} / 2 \mathrm{~J}$ and $\mathrm{C} 57 \mathrm{Bl} / 6 \mathrm{~J}$ mice at 21 and 70 days are illustrated in Table 1. The supernatant HMT value of the SS DBA/2J mice at 21 days of age was significantly lower than that of the SR DBA/2J mice at 70 days, but not significantly different from that of the SR C57Bl/6J mice at 21 days. Furthermore, while there was a significant increase in HMT activity levels between the 21- and 70-day old animals within each strain, there was no significant difference between the HMT values of the $\mathrm{DBA} / 2 \mathrm{~J}$ and $\mathrm{C} 57 \mathrm{Bl} / 6 \mathrm{~J}$ mice at either 21 or 70 days. There was no significant difference in the homogenate of 21-vs 70-day old DBA/2J mice (data not shown).

As illustrated in Table 2, the specific activity of HMT was consistently lower in the SS Peromyscus than in the comparable SR Peromyscus animals whether tested in the homogenate or in the high-speed supernatant. Complementary data for Mus regarding COMT and MAO, types A and $B$, are shown in Table 3 . The DBA/2J animals exhibited significantly lower COMT values than the $\mathrm{C} 57 \mathrm{Bl} / 6 \mathrm{~J}$ mice at both 21 and 70 days, confirming the work of Schlesinger et
TABLE 1

CEREBRAL HISTAMINE N-METHYLTRANSFERASE IN DBA/2J AND C57BV/6J MICE*

\begin{tabular}{lcc}
\hline Mouse Strain & \multicolumn{2}{c}{ Age, days } \\
& 21 & 70 \\
\hline $\mathrm{DBA} / 2 \mathrm{~J}$ & $5.66 \pm 0.45^{1}$ & $6.78 \pm 0.10^{2}$ \\
$\mathrm{C} 57 \mathrm{Bl} / 6 \mathrm{~J}$ & $5.48 \pm 0.10^{3}$ & $6.33 \pm 0.17^{4}$ \\
\hline
\end{tabular}

${ }^{*}$ nmoles product $/ \mathrm{hr} / \mathrm{mg}$ protein of mean $\pm \mathrm{SEM}$ assayed in supernatant fraction in 4-6 animals. The following comparisons were significantly different at $p<0.05: 1$ vs 2,3 vs 4 .

TABLE 2

CEREBRAL HISTAMINE N-METHYLTRANSFERASE IN THE AUDIOGENIC SEIZURE-SUSCEPTIBLE (SS) $v s$ RESISTANT (SR) Peromyscus

\begin{tabular}{lcc}
\hline Fraction & SS & SR \\
\hline Homogenate & $1.66 \pm 0.11$ & $1.97 \pm 0.08 \dagger$ \\
Supernatant & $5.56 \pm 0.38$ & $6.64 \pm 0.17^{\dagger}$ \\
\hline
\end{tabular}

${ }^{*}$ nmoles product $/ \mathrm{hr} / \mathrm{mg}$ protein of mean $\pm \mathrm{SEM}$ in $6-7$ sixty day-old animals.

$†$ denotes significance at $p<0.05$, relative to SS animals.

al. [18]; there was, however, no significant difference in the $\mathrm{DBA} / 2 \mathrm{~J}$ mice at 21 vs 70 days. Table 3 shows that MAO, type $B$ (substrate phenylethylamine) was also significantly lower in the brains of the 21-day old SS DBA/2J mice when compared to either 21-day old SR C57Bl/6J or 70-day old SR $\mathrm{DBA} / 2 \mathrm{~J}$ animals. It should be noted, however, that there was no significant age-related difference in MAO, type B activity in the $\mathrm{C} 57 \mathrm{Bl} / 6 \mathrm{~J}$ mice. Table 3 also shows a difference in the specific activity of MAO, type A between 21- and 70-day old $\mathrm{DBA} / 2 \mathrm{~J}$ mice. This observation is to be compared to the findings of Schlesinger et al. [18] who reported no difference in the activity of cerebral 5-hydroxytryptamine-preferring (MAO, type A) enzyme between $\mathrm{C} 57 \mathrm{Bl} / 6 \mathrm{~J}$ and $\mathrm{DBA} / 2 \mathrm{~J}$ mice and of Kellogg [6] who described significantly higher MAO, type $A$ values in 21 -day old $S R$ C $57 \mathrm{~B} 1 / 6 \mathrm{~J}$ mice relative to $\mathrm{DBA} / 2 \mathrm{~J}$ SS mice of the same age.

TABLE 3

CEREBRAL CATECHOL-O-METHYLTRANSFERASE (COMT) AND MONOAMINE OXIDASE (MAO), TYPES A AND B IN DBA/2J AND C57Bl/6J MICE*

\begin{tabular}{lccccc}
\hline Mouse strain & $\begin{array}{l}\text { Age, } \\
\text { days }\end{array}$ & COMT & MAO, type A & MAO, type B \\
\hline $\mathrm{DBA} / 2 \mathrm{~J}$ & (SS) & 21 & $1.72 \pm 0.03^{1}$ & $1.68 \pm 0.51^{5}$ & $4.04 \pm 0.12^{7}$ \\
$\mathrm{C} 57 \mathrm{Bl} / 6 \mathrm{~J}$ & (SR) & 21 & $2.41 \pm 0.01^{2}$ & n.d. & $4.98 \pm 0.37^{8}$ \\
$\mathrm{DBA} / 2 \mathrm{~J}$ & (SR) & 70 & $1.60 \pm 0.05^{3}$ & $13.7 \pm 0.50^{6}$ & $5.02 \pm 0.32^{9}$ \\
$\mathrm{C} 57 \mathrm{Bl} / 6 \mathrm{~J}$ & (SR) & 70 & $2.14 \pm 0.03^{4}$ & n.d. & $4.09 \pm 0.31^{10}$ \\
\hline
\end{tabular}

${ }^{*}$ nmoles product $/ \mathrm{hr} / \mathrm{mg}$ of protein of mean \pm SEM in 4-6 animals per group. The following comparisons were significantly different at $p<0.05: 1$ vs 2 ; 1 vs $4 ; 2$ vs $4 ; 3$ vs $2 ; 3$ vs $4 ; 5$ vs $6 ; 7$ vs $8 ; 7$ vs 9 .

SS: seizure-susceptible.

SR: seizure-resistant.

n.d.: not determined. 
TABLE 4

CEREBRAL CATECHOL-O-METHYLTRANSFERASE (COMT) AND MONOAMINE OXIDASE (MAO), TYPES A AND B IN SS AND SR Peromyscus*

\begin{tabular}{llll}
\hline Animal & COMT & MAO, type A & MAO, type B \\
\hline SR & $1.81 \pm 0.04(7)$ & $15.4 \pm 0.98(8)$ & $6.02 \pm 0.36(9)$ \\
SS & $2.71 \pm 0.10(6) \dagger$ & $16.6 \pm 1.23(7)$ & $5.55 \pm 0.45(8)$ \\
\hline
\end{tabular}

${ }^{*}$ nmoles product $/ \mathrm{hr} / \mathrm{mg}$ of protein of mean \pm SEM. Animals were 60 days old.

$\nmid$ Denotes a significant difference at $p<0.05$. The numbers in parenthesis refer to the number of animals.

The activities of COMT, MAO, type A and type B in Peromyscus brain (Table 4) indicate a significant elevation of COMT in the SS animal and no evident difference in either type of MAO.

To summarize, we report significantly lower HMT activities in the brains of two different SS animal models and a significantly higher COMT activity in the SS than in the SR Peromyscus brain. In addition, we demonstrate that the activity of cerebral MAO, type $\mathrm{B}$, the enzyme responsible for the conversion of cerebral 3-methylhistamine to 3-methylimidazoleacetic acid [5,21] is significantly lower in the 21-day old SS DBA/2J mice than in the 70-day old SR animals.

It should be noted that within $M u s$ and Peromyscus there are different genetic models of seizure susceptibility [7, 9, 17, 20]. The multiformity of results obtained when data is compared across different seizure models may thus be reflective of the genetic diversity evident in the inherited epilepsies. A similar multiformity of results exists within the literature of non-inherited, electrically or chemically elicited seizures [22]. Our demonstration of abnormalities of cerebral methyl group transfer reactions in both a chemically induced (MSO) and a genetically derived seizure state (audiogenic seizures in Peromyscus) should greatly facilitate the search to understand the relationships between biochemical and genetic mechanisms of seizure susceptibility. Work is in progress to further elucidate the nature of cerebral methylation reactions in Peromyscus as they may relate to this trait.

\section{ACKNOWLEDGMENT}

This research was supported by grant NINCDS-06294 from the United States Public Health Service.

\section{REFERENCES}

1. Barto, E. Tests for independence of "waltzer" and "ep" sonogenic convulsions from certain other genes in the deermouse Peromyscus maniculatus. Contr. Lab. vertebr. Biol. Univ. Mich. 74: 1-15, 1956.

2. Consroe, P. and H. L. Edmonds. Genetic animal models of epilepsy. Fedn Proc. 38: 2397-2398, 1979.

3. Dainat, J., C. E. Salas and O. Z. Sellinger. Alteration of the specificity of brain tRNA methyltransferases and of the pattern of brain tRNA methylation in vivo by methionine sulfoximine. Biochem. Pharmac. 27: 2655-2658, 1978.

4. Doyle, R. L. The Role of Biogenic Amines in an Audiogenic Seizure-prone Genotype of Peromyscus Maniculatus, With an Analysis of the Protective Effects of Phenobarbital and Diphenylhydantoin. Ph.D. Dissertation, University of Michigan, 1978, pp. 1-69.

5. Hough, L. B. and E. F. Domino. Tele-methylhistamine oxidation by type B monoamine oxidase. J. Pharmac. exp. Ther. 208: 422-428, 1979.

6. Kellogg, C. Serotonin metabolism in the brains of mice sensitive or resistant to audiogenic seizures. J. Neurobiol. 2: 209-219, 1971.

7. King, J. Biology of the Peromyscus. Society of Mammalogists Publication No. 10., 1968.

8. Lowry, O. H., N. J. Rosebrough, A. L. Farr and R. J. Randall. Protein measurement with the Folin reagent. J. biol. Chem. 193: 265-275, 1951.

9. Noebels, J. L. Analysis of inherited epilepsy using single locus mutations mice. Fedn Proc. 38: 2405-2410, 1979.

10. Owen, F., R. C. Bourne, J. C. K. Lai and K. Williams. The heterogeneity of monoamine oxidase in distinct populations of rat brain mitochondria. Biochem. Pharmac. 26: 289-292, 1977.

11. Porcher, W. and A. Heller. Regional development of catecholamine biosynthesis in rat brain. $N$. Neurochem. 19: 1917-1930, 1972.

12. Saavedra, J. M., M. J. Brownstein and M. Palkovits. Distribution of catechol-O-methyltransferase, histamine N-methyltransferase and monoamine oxidase in specific areas of the rat brain. Brain Res. 118: 152-156, 1976.
13. Salas, C. E., W. G. Ohlsson and O. Z. Sellinger. The stimulation of cerebral $\mathrm{N}^{2}$-methyl and $\mathrm{N}_{2}{ }^{2}$-dimethylguanine-specific tRNA methyltransferase by methionine sulfoximine: an in vivo study. Biochem. biophys. Res. Commun. 76: 1107-1115, 1977.

14. Schatz, R. A. and O. Z. Sellinger. Effect of methionine and methionine sulphoximine on rat brain S-adenosyl-L-methionine levels. J. Neurochem. 24: 63-66, 1975.

15. Schatz, R. A. and O. Z. Sellinger. The elevation of cerebral histamine $\mathrm{N}$ - and catechol-O-methyltransferase activities by L-methionine-dl-sulfoximine. J. Neurochem. 25: 73-78, 1975.

16. Schatz, R. A., K. Frye and $O$. Z. Sellinger. Increased in vivo methylation of ${ }^{3}(\mathrm{H})$ histamine in the methionine sulfoximine epileptogenic mouse brain. J. Pharmac. exp. Ther. 207: 794 $800,1978$.

17. Schlesinger, K. and B. J. Griek. The genetics and biochemistry of audiogenic seizures. In: Contribution to Behavior-Genetic Analysis: The Mouse as a Prototype, edited by G. Lindzey and D. D. Thiessen. New York: Appleton-Century-Crofts, 1970, pp. 219-259.

18. Schlesinger, K., J. Harkings, B. S. Deckard and C. Paden. Catechol-O-methyltransferase and monoamine oxidase activities in brains of mice susceptible and resistant to audiogenic seizures. J. Neurobiol. 6: 587-596, 1975.

19. Sellinger, O. Z., R. A. Schatz and W. G. Ohlsson. Rat and mouse brain histamine $\mathrm{N}$-methyltransferase: modulation by methylated indoleamines. J. Neurochem. 30: 437-445, 1978.

20. Seyfried, T. N. Audiogenic seizure in mice. Fedn Proc. 38: 2399-2404, 1979.

21. Waldmeier, P. C., J. J. Feldtrauer and L. Maitre. Methylhistamine: evidence for selective deamination by MAO B in the rat brain in vivo. J. Neurochem. 29: 785-790, 1977.

22. Woodbury, D. M. Convulsant drugs: Mechanisms of action. In: Antiepileptic Drugs, Mechanisms of Action, edited by G. H. Glaser, J. K. Penry and D. M. Woodbury. New York: Raven Press, 1980, pp. 249-302. 